María Cecilia Rossi,

Cuadernos de $\mathrm{H}$ Ideas, vol. 11, $\mathrm{n}^{\circ}$. 11, e007, diciembre 2017

ISSN 2313-9048 | https://doi.org/10.24215/23139048e007

http://perio.unlp.edu.ar/ojs/index.php/cps/index

FPyCS | Universidad Nacional de La Plata

La Plata | Buenos Aires | Argentina

\title{
Las estrategias de las familias borbónicas para acceder al poder del Cabildo. Un estudio de caso en el Santiago del Estero durante la segunda mitad del siglo XVIII.
}

\section{The strategies of the Bourbon families to access the power of the Cabildo. A case study in the Santiago del Estero during the second half of the 18th century}

\begin{abstract}
María Cecilia Rossi
Academia Nacional de la Historia, Instituto de Investigaciones en Humanidades y Ciencias Sociales, Centro de Historia Argentina y Americana, Universidad Nacional de La Plata, Argentina. Centro de Estudios de Demografía y Población, Facultad de Humanidades, Ciencias Sociales y de la Salud, Universidad Nacional de Santiago del Estero. Contacto: mcrhecker@gmail.com
\end{abstract}

\section{Resumen}

En este trabajo se estudian las estrategias de dos agentes borbónicos para arribar y consolidar el poder local. Se trata de un estudio de caso referido al Cabildo de Santiago del Estero, que muestra -en parte- la conformación de la elite local a partir del establecimiento de lazos familiares durante la segunda mitad del siglo XVIII. Entre otras fuentes se utilizan las Actas Capitulares del Cabildo de Santiago del Estero y expedientes tanto del Archivo Histórico de Santiago del Estero, como del Archivo General de la Nación.

Palabras clave: Familias; estrategias; poder; Cabildo; Santiago del Estero.

\section{Abstarct}

In this paper we study the strategies of two Bourbon agents to arrive and consolidate local power. It is a case study referred to the Cabildo of Santiago del Estero, which shows -in partthe conformation of the local elite from the establishment of family ties during the second half of the 18th century. Among other sources, the Chapter Acts of the Cabildo of Santiago del 
Estero and records of both the Historical Archive of Santiago del Estero and the General Archive of the Nation are used.

Keywords: Families; strategies; power; Cabildo; Santiago del Estero.

En este trabajo estudiamos a dos agentes borbónicos, don Joseph Miguel Zilveti Pedraza Giraldes, oriundo del reino de Chile donde nació en 1737 y arribado a Santiago en 1758 y a don Francisco Antonio de Zuasnábar Ayarragaray, nacido en 1728 en Hernani, Guipúzcoa, España que llegó a Santiago promediando la década de 1750.(1) Ambos ostentaban el grado de Sargento Mayor, de modo que su incorporación al fuero militar local debe haber sido inmediata.(2)

Cuando hacían sus primeras armas en el Cabildo, de ambos dirán los capitulares que eran muy buenos jóvenes, pero "insolventes". Cada uno a su tiempo modificará esta caracterización al contraer matrimonio con dos hermanas, Joseph Miguel se casó con María Catalina y Francisco Antonio con María Petrona, las jóvenes Paz y Figueroa Díaz Caballero Ledesma Valderrama, hijas del matrimonio del Sargento Mayor y capitular santiagueño don Miguel de Paz y Figueroa Figueroa Mendoza y de Doña María Díaz Caballero Ledesma Valderrama, una familia de fortuna en decadencia pero con un gran capital simbólico y linaje que las ligaba a los tiempos iniciales de la conquista y a todos los más grandes actores de la política del Tucumán, de Perú y de Chile.(3) El matrimonio los convertirá en vecinos,(4) allanándoles el camino para los privilegios, las acciones capitulares, comerciales, y corporativas en general, antecedentes familiares a los que recurrirán en cada oportunidad que tengan que reclamar por algún cargo, peticionar al rey, o realizar algún trámite de usanza.

El interés por esta pareja de agentes del orden borbónico tiene que ver con los modos en que articularon las cuestiones de parentesco con el desempeño de una importantísima actividad de cooptamiento en el Cabildo en el año 1772. Tal actividad logrará implementar la mayor parte de las Reformas Borbónicas que hasta el momento se habían visto muy obstaculizadas localmente por los criollos que formaban el "estado criollo", muchos de los cuales eran sus propios familiares quienes defendían los propios derechos corporativos.

Retomamos aquí el planteo de Juan Hernández Franco en relación a la importancia del "reencuentro entre historia social e historia política en torno a las familias de poder", buscando comprender las relaciones establecidas por las familias borbónicas-criollas en la institución capitular y el rol fundamental que en ella adquieren las relaciones de parentesco.(5) Además de la utilización de estos mecanismos en el juego de reconocimiento y la legitimidad de los agentes involucrados, la obtención de ventajas y beneficios personales y familiares que los terminan reforzando como elementos claves para la consolidación de la propia familia y la reproducción social. Pero además, y siguiendo a Francisco Andújar del Castillo nos interesa 
estudiar a ambos agentes y sus familias como elites de poder(6) no solo en el momento preciso que se instalan en la cúspide capitular, sino recorrer con ellos el proceso hasta llegar al lugar que les permitió instalar el conjunto de reformas.

Con este artículo estamos dando continuidad a las investigaciones iniciadas sobre la familia Zilvetti Pedraza Giraldes Paz y Figueroa Díaz Caballero, en uno de los puntos que dejamos abierto en un artículo anterior,(7) sobre el accionar en el Cabildo santiagueño, mientras que iniciamos los estudios de la familia Zuasnábar Ayarragaray Paz y Figueroa Díaz Caballero y Ledesma Valderrama.

Para realizar esta investigación recurriremos a los aportes documentales de las Actas Capitulares de Santiago del Estero y de documentación obrante en el Archivo Histórico de Santiago del Estero, en sus Secciones Hacienda Asuntos Generales y Tribunales, y del Archivo General de la Nación, además del enorme valor de las genealogías.

\section{1- Los agentes borbónicos en Santiago del Estero y la conformación de sus respectivas familias.}

Los Sargentos Mayores don Francisco Antonio Zuasnábar Ayarragaray y don Joseph Miguel de Zilveti Pedraza Giraldez se instalaron en la ciudad de Santiago del Estero con pocos años de diferencia. El primero lo hizo a mediados de 1750 y el segundo a fines de 1758 . Agentes con altos grados militares y poca fortuna enviados por el Imperio a desarrollar tareas militares y luego capitulares de singular importancia, contrajeron matrimonio con las hermanas Paz y Figueroa Díaz Caballero Ledesma Valderrama, cuyas familias formaban parte de la elite criolla más encumbrada localmente con notable influencia tradicional en el Cabildo. Ambos matrimonios tuvieron una numerosa descendencia, Zuasnábar Paz y Figueroa con ocho hijos: Francisco, María Roberta, Gabriela, Margarita, Victoria, Juan Manuel, Xaviera y Gregoria. Zilveti Paz y Figueroa por su parte tuvo siete (de los cuales vivieron cinco), María Jacinta, Juan Joseph, Buena Ventura, Juan Rudecindo, Bernarda, María Antonia, Joseph Torcuato.

Si bien no es nuestro propósito en el presente trabajo desarrollar los entramados familiares, diremos que hubo en ambas familias unas estrategias matrimoniales que aparecen muy claras. La opción por los vascos borbónicos fue la primera de ellas, la de los criollos de la elite local fue la segunda. Resultó significativo advertir los cruces dentro de una misma familia teniendo como eje a otro vasco borbónico, don José Pelayo de Alcorta Larrañaga, nacido en 1755 en Guetaría, Guipúzcoa, comerciante y desde 1787 Administrador de Correos de Santiago, además de Síndico del Convento de San Francisco.(8) 
Serán entonces, Gabriela de Zuasnábar Paz y Figueroa y María Jacinta Zilveti Paz, las grandes constructoras de redes que, además, dieron a la provincia y al país actores de renombre. Gabriela fue madre de un gobernador don Manuel Alcorta Zuasnábar, en 1830 y abuela de otro pues Manuel, en su segundo matrimonio con María Jesús Gallo Ispizua fueron padres de don Pedro Ramón Alcorta Gallo, gobernador de la provincia en 1860. Otro hijo muy reconocido de Gabriela fue don Amancio Jacinto de Alcorta Zuasnábar, cuyo nombre fue popularizado como Amancio Alcorta, que formó parte de la primera generación de músicos nacidos en territorio rioplatense, literato, representante de la provincia en distintos congresos y senador desde 1853. Respecto de María Jacinta, uno de sus hijos, don Pedro José Laureano Alcorta Zilveti, Alcalde Ordinario en Santiago en 1823 y luego Tesorero del gobierno de Juan Felipe Ibarra y los comienzos del Taboadismo, en su segundo matrimonio con María del Tránsito Isnardi Corvalán, fue padre de Teodosia Alcorta Isnardi quien fue casada en Córdoba con don José Cornelio de Figueroa Valverde y fueron padres del Presidente de la República don José María Cornelio Figueroa Alcorta (1906-1910).

\section{2-El mundo institucional.}

Es nuestra intención, en esta primera parte del mundo institucional, caminar junto a nuestros dos agentes del orden borbónico, para analizar, desde la mayor cercanía posible, esa construcción interna que hicieron en el Cabildo, desde su ingreso hasta 1772. Aquí debemos tener en cuenta una cuestión. Hasta el momento, las históricas pugnas entre facciones en el Cabildo se daban entre los propios integrantes de las distintas facciones criollas que batallaban por los lugares de mayor privilegio, a los que nosotros vemos en los registros como individuos, pero eran, en realidad, los emergentes, no solo de las disputas muchos más amplias sino que involucraban a las distintas redes sociales de pertenencia. Pero, si había en Santiago una familia que a esta altura representaba la continuidad del Estado Criollo empeñadísimo en no desaparecer, era la de los López de Velasco.

\section{1-Entre la homogamia de la elite criolla y las crisis de representación.}

El Cabildo atravesaba una época en donde la representación política estaba sumamente complicada. En 1756 la institución estalló por la cuestión de los parentescos. El Alcalde de

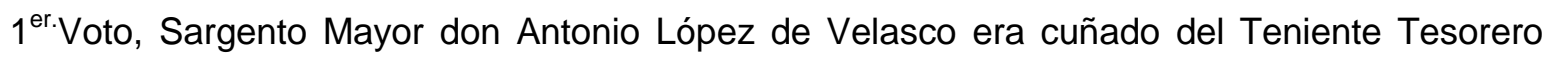
don Agustín Salvatierra casado con Sebastiana López de Velasco, los tres vocales en ejercicio eran hermanos, Antonio, Roque y Joseph López de Velasco y cuñados del Teniente Tesorero. 
En el mismo embrollo estaba el Maestre de Campo don Juan José Paz y Figueroa Ibáñez del Castrillo, Alférez Real Propietario,(9) que era cuñado de los López de Velasco(10) casado en segundas nupcias con doña Clara López de Velasco Sánchez Zambrano.(11)

Cinco años más tarde, en 1761 nuevamente tenemos una situación muy complicada e insólita en el Cabildo que había quedado sin jueces, por lo que la institución decidió convocar a los vecinos para ver si podían habilitar a alguien que administrara justicia. Por las dudas, rápidamente nombraron un Carcelero, para que cuidara que los presos no se escaparan. Había muy pocos vecinos residiendo en la ciudad, ya que se había profundizado la preferencia por la vida en sus estancias y eran escasos los que estaban en condiciones de oficiar como jueces. A ello habría que sumar que la mayoría tenía deudas con el Estado, o se ocupaban de sus comercios o actividades en el campo que le podían resultar más redituables. Ciertamente, era un periodo sumamente complejo para Santiago en materia económica, financiera, comercial; signada por la pobreza y las carencias, y estas cuestiones no dejaban afuera a la elite. Los Libros de Tesorería dan cuenta de los escasos ramos que se contabilizaban y la poca recaudación que en ellos consta.(12) Pero también de los manejos y desmanejos de los fondos públicos en beneficio propio, aunque, como dijera Bertrand,(13) el imperio dictaba una cantidad de normas orientadas a controlar los dineros públicos, pero toleraba un cierto grado de corrupción a la que había naturalizado sabiendo que era una forma que los funcionarios mejoraran sus ingresos y su calidad de vida.

Entre los hombres que ya habían sido jueces en una o varias oportunidades se advirtió que los posibles de ser elegidos, ya sea porque habían tenido buen desempeño o eran simplemente familiares o formaban parte de la elite, eran mayores de edad y algunos estaban muy enfermos, y por lo mismo incapacitados para volver a ejercer. Tampoco parecía haber entre los más jóvenes demasiado interés ni compromiso con la institución ni con el propio grupo que trataba de contenerlos. Esto inquietó sobremanera a los viejos y poderosos criollos. No sabían muy bien cómo actuar y daban vueltas sobre ellos mismos buscando quien cubriera los cargos. Ante un panorama tan desolador, produjeron una nueva concentración de cargos en sus propias manos, la que, girando sobre sí misma, incitó su propio encierro de poder.(14) Lo que estaba emergiendo era una cuestión mucho más profunda aun, que la problemática del parentesco. Se trataba de la muerte, tan simbólica como real, del poder criollo en Santiago.

\section{2- Estrategias en el Cabildo}

Nuestros dos agentes ingresaban al Cabildo y podemos comenzar a entrever sus estrategias institucionales. En 1762 el Sargento Mayor don Francisco Antonio Zuasnábar Ayarragaray formará parte de los siete "vecinos de excepción" convocados para la 
elección,(15) y fue electo como Procurador General; en 1763 don Jospeh Miguel Zilveti Pedraza Giraldes iniciaba su carrera en la administración de la justicia rural al ser electo Alcalde de la Santa Hermandad;(16) en 1764 Zuasnábar fue electo Procurador General y Mayordomo del Real Hospital. En 1765 ya los vemos a los juntos participando como vocales elegidos por el vecindario para las elecciones de Alcaldes Ordinarios de la Santa Hermandad y otros oficios, pero también estaban entre los "elegibles", aunque de Zuasnábar dirán los mismos capitulares que no lo veían con buenos ojos ya que opinaban que era "mozo muy honrado y buen vecino" pero "insolvente".(17) Aun así fue nombrado Alcalde de $1^{\text {er. }}$ Voto mientras Zilveti se convertía en Protector de Indios, nombramiento que trajo sorpresas ya que a los pocos meses le quitaron el título advirtiendo que no era "lenguaraz" y nunca había pasado que el Protector no fuera lenguaraz,(18) los indios quedaron desprotegidos y le elevaron al gobernador la consulta sobre qué actitud tomar al respecto. Se resuelve interinamente nombrar a don Joseph de Frías.(19)

De modo que podríamos pensar que lo que ocurrió fue una suerte de arreglo interno para darle un lugar en la institución.(20) Para ésta época ya Zuasnábar Ayarragaray había ingresado en la zona de rotación de cargos capitulares y en 1766 lo veremos actuando como Procurador General de la Ciudad cuando Carlos III había ordenado el repoblamiento de todas las ciudades del imperio, correspondiéndole a nuestro agente iniciar el proceso en Santiago del Estero, lo que significaba obligar a los vecinos que vivían en sus estancias a volver a volver a vivir en la ciudad. Complejo. Muy complejo. Además presentó un título como Teniente Tesorero de la Real Hacienda.(21) Pocos meses después y con el cargo de Tesorero en ejercicio, fue electo nuevamente como Alcalde ordinario y Zilvetti como Alcalde de la Santa Hermandad.(22)

A esta altura ya podemos notar una diferencia en el accionar capitular entre ambos agentes del orden borbónico, porque mientras que Zuasnábar tendrá una actividad bien urbana, a Zilvetti lo vemos moverse en el área rural.

\section{3-Los Borbónicos al poder.}

Ya lo había explicado Linch que desde la década de 1760 aquellos hombres que emigraban a América, "se inmiscuyeron en los derechos de los criollos y en su posición económica"; aumentó el poder del Estado y se aplicaron mayores controles imperiales.(23) Las nuevas directrices del gobierno de Carlos III significaban el potencial recorte de las muy afianzadas prácticas criollas que se venían desarrollando desde 1650, por mencionar una solamente, la de obtener por compra los mayores y mejores cargos, rol que en adelante 
comenzarán a jugar los borbónicos, se tratara de los agentes recién llegados o hijos de la primera generación de familias borbónico-criollas.

De modo que los veremos ubicarse en cargos por sobre la estructura capitular, cargos rentados y a los que se accedía, generalmente, por compra o alquiler. En 1761 don Agustín de Iramain Rodríguez Espinosa presentó el título de teniente Tesorero de los Oficiales Reales de la ciudad.(24) O en 1764 don Francisco Ximénez de Paz Parejas llegó con una Real Cédula por la cual se lo nombraba Juez Comisionado de Residencia, para residenciar la actividad del ex gobernador Martínez de Tineo, y todos los que lo habían acompañado.(25) En ese mismo año sumó otro cargo, el de Escribano Público, otorgado por el gobernador y arrendado por tres años.

También sostiene Linch que en cada región estos procesos se fueron llevando a distintos ritmos, y para Santiago, éstos movimientos ordenados por el orden imperial borbónico que dimos en llamar el fin del Estado Criollo, tuvo su manifestación más fuerte y visible durante las elecciones para capitulares en 1772, realizada en los últimos días de diciembre del año anterior, como era de práctica.

Fue en este momento cuando el parentesco y la política borbónica se unieron para encajonar el poder de los antiguos criollos y tener, hacia adelante, en sus manos la posibilidad de imponer las reformas de Carlos III. Las complejidades en las relaciones entre las facciones criollas, y particularmente las disputas de don Roque López de Velasco y sus hermanos y familiares directos o indirectos, tendrán un freno brusco en estas elecciones y año venidero. ¿Significaría esto que los criollos desaparecerían del escenario político? En absoluto, seguiremos viendo a muchos criollos participando por muchos años más todavía, pero realizando movimientos de plegamiento a las políticas imperiales (algunos más discretos que otros) y trabajando junto a los hijos de la primera y segunda generación de hijos de familias borbónico-criollos.

Cinco años más tarde, relativamente tranquilizado el ambiente había llegado la hora de terminar de imponer esa serie de reformas. En este contexto, los concuñados y agentes borbónicos, don Francisco de Zuasnábar Ayarragaray y Jospeh Miguel Zilveti Pedraza Giraldes fueron, mirado el asunto desde los intereses imperiales, los dos grandes actores del proceso. El primero actuando como vecino elector resultó electo Alcalde de $1^{\text {er. }}$ Voto y el segundo como Comisionado por el gobernador para verificar la elección. De otro lado, los actores del grupo criollo liderados por don Roque López de Velasco, en completa y absoluta oposición ante la maniobra imperial.

Pero, en el último tiempo del año 1771 se sublevaron todos los grupos indígenas de la frontera del río Salado, reducidos hasta unos años antes por los Jesuitas. Al mismo tiempo, se preparaba una nueva embestida del grupo criollo capitular. Dos núcleos muy fuertes que 
los borbónicos, con el respaldo del gobernador, se prepararon para contener -en principio- y doblegarlos casi inmediatamente.

\subsection{1-El Cabildo paralelo.}

En tiempos paralelos las cuestiones que relatamos en párrafos anteriores, se produjeron las acciones en el Cabildo. Había una serie de reformas imperiales que no podían implementarse en Santiago por la fortaleza de los intereses defendidos por el grupo capitular criollo liderado por don Roque López de Velasco. Aquí recuperamos la actuación de nuestros dos agentes, Zilvetti Pedraza Giraldes y de Zuasnábar Ayarragaray. El último día del año 1771 encontramos en el recinto capitular a los funcionarios más los vecinos que realizarían la elección de los tres Regidores que por el pueblo participarían en la elección de los capitulares para 1772.

$\mathrm{Ni}$ bien iniciada la reunión, Zuasnábar Ayarragaray pidió permiso para ingresar y presentó una Provisión del gobernador que lo confirmaba como verificador y confirmador de las elecciones a realizar. Cuando las autoridades capitulares lo aceptaron, un grupo se levantó y se fue de la Sala fue diciendo que realizarían la elección desde su casa.(26) Qué diría esta Provisión en su "letra chica"? Sabemos que no fue copiada en el Acta y que enojó sobremanera a algunos capitulares y otros electores. A este grupo sublevado, todavía no identificado, le siguió otro de los electos quedando el Alcalde de $1^{\text {er. }}$ Voto don Miguel de Iramain. En esas condiciones se realizó la elección capitular que fue firmada (imaginamos que con posterioridad) por Joseph Ignacio Lazcano, Claudio de Medina y Montalvo, Francisco Javier Gramajo, Pedro Joseph de Luna, Fernando Bravo de Zamora, Juan Joseph de Paz y Zurita, Agustín Salvatierra, Bartolomé Francisco Maguna, Ramón Bravo, el único borbónico presente era Joseph Miguel Zilvetti.(27)

Luego Zuasnábar Arrayagaray confirmó la elección en su calidad de Comisionado de Su señoría Joaquín de Espinosa y Dávalos para el día siguiente, $1^{\circ}$ de enero de 1772 , diciendo en el escrito elevado al gobernador "...que se ha actuado con toda libertad según previenen las leyes acompañado del Señor Presidente para la regulación de votos de Regidores (los electores) fueron el Maestre de Campo don Claudio de Medina y Montalvo, el Sargento Mayor don Joseph Miguel de Zilvetti y el capitán don Bartolomé Francisco de Maguna, actual defensor de menores..." y les tomaron el correspondiente juramento.(28)

Siguiendo el relato de las Actas Capitulares podría afirmar que no habría ocurrido nada extraño, todo se había desarrollado con normalidad y los cabildantes actuado con libertad (nada se vuelve a decir sobre los que se fueron), mientras el propio Zuasnábar no habría intervenido en ninguna instancia.(29) Ahora bien. Recuperando los relatos de los opositores, 
se advierte que lo ocurrido fue una verdadera ruptura del aparato del Estado Criollo, resuelta a favor de los intereses imperiales y las ordenes de Carlos III.

Veamos cómo sigue esta historia. Comenzaba la jornada del $1^{\circ}$ de enero de 1772 , cuando se realizaba la primera reunión del año en que se debía de confirmar la elección de los capitulares. En la Sala Capitular se fueron haciendo presentes los Regidores y los electos en la reunión del día anterior y se abrió la sesión. Aunque, para sorpresa de todos, unos momentos antes de que se pasaran a las confirmaciones, se "leyó un libelo...en forma de

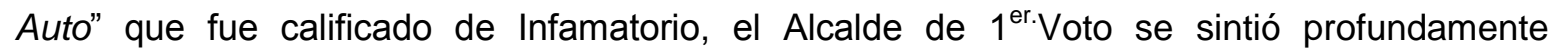
afectado y así lo expresó claramente, tildándolo de falso de todo falsedad, “...le protexte en la parte que me tocaba, de Nulidad, Repetidas Veces.... Entendido como una directa amenaza contra los electos en su conjunto, además pedía que se vayan también los vecinos convocados como electores.

Todo nos indica que el libelo provenía del grupo opositor, de aquel que se había retirado muy ofuscado el día anterior a realizar el Cabildo paralelo, que acusaba de nulidad a la elección realizada en el día anterior, que, a pesar de la normalidad y la libertad afirmada por Zuasnábar, debía haberse realizado en un clima enrarecido porque cuando dejaron abruptamente la sesión se fueron abandonando la Sala y dejando la Casa Capitular abierta, incluso quedó abierto el Archivo, y se llevaron a esa casa particular la lista para desde allí elegir las autoridades. Objetivamente, ocurrió que este grupo opositor lo era, en principio, a Zuasnábar y las cuestiones que defendía, porque lo dejaron solo diciéndole que hiciera lo que quisiese. Esto nos permite inferir que Zuasnábar estaba no solo controlando el buen desarrollo e las elecciones, sino tomando decisiones que parte de los posibles regidores electos, cuestionaban.

Luego de semejante conmoción volvieron a retirarse los opositores a la lista que se estaba por confirmar decidiendo armar otra lista desde este Cabildo Paralelo que, según todo indica, funcionaba en casa de Roque López de Velasco. Es una historia muy fuerte, porque se trataba del desconocimiento efectivo de las directivas reales.

La continuidad de la lectura señala que los capitulares insurrectos estaban capitaneados por el Regidor 24 don Roque López de Velasco en cuya casa se habían reunido, y realizaban una serie de peticiones, como que se quitara de la lista al Alcalde Provincial que estaba al frente de las Temporalidades y cuatro de los vecinos citados para la elección de los Regidores, formaban la Junta Municipal: los generales don Antonio García de Villegas, don Manuel del Castaño, don Francisco de Paz y don Baltazar Gaya. Y aquí encontramos una de las pistas más firmes del grupo opositor: el poder borbónico había subsumido la autoridad del Cabildo y de la Junta en los mismos electores, lo que enardeció a los criollos. Y como si esto fuera poco, ejercieron un fuertísimo acto intimidatorio poniendo en la puerta del Cabildo una 
Compañía de soldados forasteros a cuyo frente estaba su Capitán don Manuel Romero, todos armados, como correspondía, tratando de modificar la situación por la violencia de las armas “...han causado sobrado Escandalo, en todo el vecindario con solo el fin de alucinarnos y salirse con sus Deprabados Intentos..."(30)

En una nueva reunión de ese mismo día, Zuasnábar no puede ocultar más la situación de clandestinidad de las elecciones en el Cabildo paralelo, y advierte que lo amenazaron para que no confirmara las elecciones ni tampoco las que ellos estaban haciendo. De modo que realizó la elección por sí mismo, diciendo “...los elijo y nombro por tales con suficiente autoridad y por ello estando congregados en esta sala capitular para el uso de dicho ejercicio les recibió juramento, que lo hicieron y celebraron según forma de derecho y por ello prometieron de usar fiel y legalmente de dicho oficio y para que conste lo firmaron conmigo..." concluyó. (31) Finalmente los electos "oficiales" se reunieron para asegurarse de no tener deudas con el fisco y otros posibles inconvenientes.

Ese mismo día $1^{\circ}$ de enero presidida por Zuasnábar se realizó una tercera reunión, como a las seis y media de la tarde, para confirmar las elecciones. Prosiguió la elección realizada por cada uno de los regidores salientes y los electos en la reunión anterior, quedando conformado del siguiente modo el Cabildo para 1722: don Joseph Miguel de Zilvetti como Alcalde de $1^{\text {er. }}$ Voto; los criollos que acompañaban se plegaron en sus prácticas al grupo borbónico, don Juan Clemente de Santillán Alcalde de 2‥ Voto; don Agustín Salvatierra Procurador General; el Sargento Reformando don Joseph Antonio de Paz y don Ramón Bravo de Zamora; los Alcaldes de la Santa Hermandad Pedro Nolasco de Argañaráz y Murguía Defensor de Menores; don Miguel Avendaño Alcalde de Aguas; don Joseph Lorenzo de Goncebat Protector de Naturales; el Sargento Mayor Reformado Joseph López de Velasco Mayordomo del Real Hospital.(32) El Cargo de Protector de Naturales se traspasó de un borbónico, Zilvetti Pedraza Giraldez, a otro borbónico, don Joseph Lorenzo de Goncebat. Luego, el Comisionado Zuasnábar declaró por aprobadas las elecciones y las firmó, tomando juramento a los electos.(33)

Ahora bien. Había llegado el momento de asentar en el Acta los acontecimientos que habían ocurrido en el día anterior y en el de la confirmación. En la misma escribieron una suerte de libreto en el que se contaba una historia de normalidades y algunos contratiempos (que no pudieron evitar del todo); dijeron lo que quisieron decir, y este no es un eufemismo sino que así expresan claramente, deciden no escribir lo que no quieren que se sepa, o lo que a las autoridades les quieren hacer saber; mientras Zuasnábar se despegaba de la historia acusando a los opositores de no querer obedecer al Auto expedido por el gobernador ni aceptar la Real Provisión imperial.(34) 
Los borbónicos dieron un fuerte golpe al grupo criollo liderado por Roque López de Velasco quien días más adelante y sin aceptar la situación intentará impedir el funcionamiento del Cabildo. Siete días más tarde, y cuando se encontraban en reunión capitular solamente dos regidores, Zilvetti y Maguna, se presentó ante las puertas del Cabildo reclamando que se lo reconociese como único Juez, ya que, recordemos, no tenían todavía la confirmación del gobernador para ejercer como Jueces, pero Zilvetti desafió abiertamente al histórico Regidor 24.(35)

Ante la serie de rotundos fracasos, don Roque López de Velasco llevó todas las actuaciones a las autoridades superiores quienes bastante rápidamente trataron de favorecerlo. Bueno. Era una actitud normal en base a sus múltiples relaciones. Sus redes con la Caja de Jujuy y la Real Audiencia eran familiares, históricas y ampliamente conocidas. Pero ésta última actitud de las autoridades nos señala que también en los altos niveles de decisión de política se atravesaba un tiempo de cambios que no había todavía terminado de cuajar completamente a favor del régimen borbónico. Tal intervención se encontró con un problema más que importante y ahora si nos queda en claro la estrategia borbónica local de la redacción de las Actas, porque en las mismas no constaban todas las acciones tomadas por ambos grupos en disputa ni todos los nombres cuestionados. De todos modos Roque y su grupo opositor no cejaron en sus intentos de anular la elección buscando las irregularidades entre las denuncias y la vía la encontraron en los vecinos electores. Poco más de un mes más tarde el Cabildo recibió una notificación del Virrey vía gobernador de Tucumán, decidiendo suspender a los Diputados Regidores que se habían nombrado en circunstancias excepcionales. Atacando el nombramiento de los diputados regidores podría anularse la elección. Pero como esa actividad era completamente temporal, para ese entonces de los tres involucrados sólo quedaba en "posesión" el General don Antonio García de Villegas, que había reunido en su persona los cargos de Notario Familiar del Santo Oficio, Administrador General de las Rentas del Correo y Diputado de la Junta Municipal de Temporalidades. De modo que, advirtieron los capitulares santiagueños, si decidían separar a García de Villegas, habría que comunicar al Presidente de las Temporalidades, el Maestre de Campo don Joseph de Garay y buscarle reemplazante en los otros dos cargos también, lo que era una complicación mayúscula y sencillamente imposible de aplicar.(36) Por su parte don Antonio García de Villegas actuó rápidamente para reforzar su posición y diez días más tarde presentó ante el Cabildo con una Real Provisión de los Oidores y Presidente de La Plata por el cual se ordenaba al Cabildo "auxiliar a las Temporalidades municipales" acción con la cual reforzaba sus relaciones institucionales.(37)

\section{4-Cuando el orden borbónico se consolida comienzan a ocurrir estas cuestiones.}


Consolidada la posición borbónica en el Cabildo y en un tiempo más que breve, se ponen en práctica una serie de reformas que estaban contenidas en su aplicación, algunas de las cuales, y solamente para referirnos al año 1772, aludiremos brevemente, la imagen y representación de las autoridades milicianas, la Iglesia como exclusivo controlador fiscal a través de la Santa Cruzada y en el marco de la Real Hacienda, el control territorial y las encomiendas y el Auto de Buen Gobierno.

\subsection{1-Imagen y representación de las autoridades milicianas borbónicas.}

Este es otro de los puntos en que se nota un cambio radical en las acciones gubernamentales y las actitudes de la población. El 10 de enero de 1772 llegó al Cabildo de Santiago del Estero un Despacho del gobernador Espinosa y Dávalos, fechado en la ciudad de Salta, nombrando al Maestre de Campo don Antonio del Castillo como Gobernador de Armas de la Ciudad y Jurisdicción. El Cabildo se organizó un espectáculo inusual hasta entonces, y solo reservado para fiestas protocolares reales, que por cierto habían sido muy pocas hasta ese entonces, la muerte de algún rey, el nacimiento de una princesa, alguna coronación, en fin, cuatro? No más a lo largo del siglo XVIII.

El escenario fue una plaza colmada de milicianos, los que quedarían bajo la nueva autoridad. Al son de caja de guerra había sido convocada la población, que llegó expectante y rodeó a los milicianos. Estaban atentos y prestos a presenciar un espectáculo completamente inusual. Claro que nadie quería perderse una fiesta tan pocas veces vista. Reunidos todos los actores, lo que incluía a las autoridades capitulares, el Alcalde de Primer Voto Zilvetti Pedraza Giraldez leyó a viva voz el nombramiento del Maestre de Campo Castillo. Lo rodeaba el mayor de los silencios, y publicó el título en forma de Bando. A una sola voz, las milicias pusieron una rodilla en tierra como signo de aceptación. En ese momento tan solemne se les preguntó si alguno estaba en contra o tenía algo que decir al respecto, y si estaban contentos de que los comandase y gobernase don Antonio del Castillo. La respuesta fue muy obvia pero contundente y así resonó en la plaza, "respondieron todos unánimes a una vez que no tenían que exponer en contra...". Luego el Alcalde de $1^{\text {er. }}$ Voto puso a Castillo en posesión del cargo, le entregó el bastón y la insignia militar que le correspondía y a continuación se escuchó un aplauso cerrado. Acto seguido, las autoridades capitulares y el electo, pasaron al interior del Cabildo para que Castillo realizara el juramento acostumbrado de fidelidad y obediencia, entre lo que se encontraba la especificación de no dar órdenes en contra del servicio real, el defender las fronteras, etc.(38) 
La asunción del nuevo Gobernador de Armas de la Ciudad y Jurisdicción, se convirtió en un espectáculo público, en el cual actores propios (las milicias) y de reparto (la población) fueron por primera vez partícipes de un "algo" que tradicionalmente se realizaba a puertas cerradas pero que sería el primero de otros actos que se reiterarían de aquí en adelante.

\subsection{2-La iglesia como controlador fiscal.}

En el marco de la reestructuración de la Real Hacienda impulsada por los Borbones, aparece la Iglesia jugando un rol recaudatorio muy importante.(39) Aquí encontramos a un criollo que rápidamente se plegará a las políticas borbónicas, don Bartholomé Francisco de Maguna, quien presentó el título de Ministro Tesorero de la Santa Cruzada,(40) concedido el 15 de enero anterior en la ciudad de Salta por el gobernador Espinoza y Dávalos, siendo sus fiadores los dos hermanos Bravo de Zamora, el Maestre de Campo don Fernando y el Sargento Mayor don Ramón, ambos muy borbónicos en los tiempos que siguen. El Cabildo le otorgó en el mismo acto todas las prerrogativas y privilegios que el cargo ostentaba, realizando las confirmaciones correspondientes el Tesorero de la Real Hacienda el Maestre de Campo don Francisco Antonio de Zuasnábar y el Alcalde de Primero Voto, Zilvetti Pedraza quien le tomó Juramento.(41)

En relación al juramento debemos confesar que no lo habíamos visto hasta el momento, pero comprensible por la historia de incumplimientos y desvío de fondos que antecede, pero además, por las nuevas disposiciones borbónicas.(42) Maguna prometió que toda la recaudación que entrara en su caja, pertenecía a su Majestad y no sería invertida en ninguna otra cuestión, salvo que el Superintendente se lo pidiera expresamente, con lo cual, al menos teóricamente, se cortaban todos los antecedentes de desvíos de fondos para cuestiones que siempre eran importantes pero más aún urgentes, como ser el arreglo de las Casas Capitulares, de la Cárcel, la acequia, en fin...Realizado el juramento se le entregó el bastón con que se distinguía un cargo de tanta importancia y una copia de su nombramiento.

Era el Ramo de la santa Cruzada una representación de la mayor importancia cuya recaudación los Borbones incluyeron dentro de Ramo de la Real Hacienda creando organismos especiales, destinados al mantenimiento de los presidios y plazas militares, a aumentar las misiones y específicamente en Tucumán, a defender la frontera de la ciudad de Córdoba.

Por último, prestemos atención a un "breve" emitido por el Papa Benedicto XIV en el año de 1750 declarando la intervención que los Oficiales Reales debían tener en la recaudación, administración y distribución del producto de bulas, llevando cuenta y razón como lo hacían con los demás Ramos de Hacienda.(43) Aquello que se había estipulado en 1750, veintidós 
años después se impondría en Santiago del Estero, justamente por haber logrado los borbónicos tomar la dirección del Cabildo.

\subsection{3-Control territorial. La hora de las encomiendas...????}

La documentación consultada nos indica que a partir de 1770 comienza una seria preocupación de las autoridades imperiales sobre el control territorial, y en ello fue el de las encomiendas, que estaban todas en manos de las más tradicionales familias criollas. Pero será en 1772 cuando el gobernador don Gaspar Varona avance sobre los títulos con que poseían los indios de sus encomiendas, porque los postulantes a cargos del funcionariado pudieran ser deudores de la Real Hacienda, y se necesitaba saber desde qué vida las poseían y que qué títulos y confirmaciones de Su Majestad para el goce de ellas en primera, segunda y tercera vida. Se les recomendó a los encomenderos que preparasen sus documentos por que el gobernador estaba saliendo para Santiago del Estero para controlar las fronteras. Mandaba que ni bien el Cabildo recibiera este documento, lo hiciera conocer por Bando, para que todos los vecinos feudatarios le presentaran al Alcalde toda la documentación y, en especial, los títulos en virtud de los cuales poseían las encomiendas. Daba un tiempo de seis días para resolver la cuestión. Los encomenderos no estaban pagando y comienza a obligárselos a pagar los tributos.(44)

Tradicionalmente personas ligadas a la conquista y a la colonización, con derechos de sus antecesores que esgrimían al momento de realizar la solicitud de tierras o de indios; linajes y aportaciones que les hicieron alcanzar una autonomía poco comparable con otras jurisdicciones; a quienes los jesuitas cuestionaron severamente por su poder y abuso de los indios; que se arrogaban el derecho de sacarlos de la jurisdicción a trabajar en otras tierras generalmente suyas y no los regresaban (hay pleitos muy conocidos al respecto), y que durante los últimos cincuenta años -por lo menos- tenían escrituras poco claras.

En un trabajo anterior mostramos que la laxitud en las posesiones, o por lo menos la falta de control sobre su cumplimiento hizo que, por una parte los encomenderos vaciaran sus encomiendas trasladando a las poblaciones a otras jurisdicciones de su posesión y en cuanto a las mercedes de tierras, por distintas tácticas fueron pasando de vida en vida dentro de la misma familia, de suerte que luego los territorios fueron conocidos por los apellidos de los poseedores, ejemplo típico fueron las tierra de los Ibarra, de los Taboada, de los Figueroa, y otros de la frontera saladina.(45) Lo cierto es que solo quedaban en el territorio veinticinco encomiendas y solo seis cumplían con la obligación de la mita aun con enorme esfuerzo de la autoridad. 


\subsection{4-Control Social. Auto de Buen Gobierno.}

Aquí vemos una última cuestión que resulta muy impresionante por la brusquedad de los cambios que se propuso. La lectura del "Auto de Buen Gobierno" para el año de 1772. El "Auto..." era un documento que emitía anualmente el Cabildo y que contenía un listado de propuestas a desarrollar a lo largo del año. Generalmente se formulaba en la primera o segunda reunión, sin haber cambiado demasiado su formato desde que disponemos de las Actas Capitulares en 1727. Sin embargo, ésta de la que vamos a hablar, que se da tardíamente, el día 23 de marzo del año 1772, casi tres meses después de iniciado el año, se trata de un documento extenso, de escritura tajante y completamente direccionado a imponer un orden social tan externo como extraño a la comunidad que pretendía ordenar. Gira sobre tres cuestiones básicas, la prohibición del vagabundeo, la obligación del conchabo y la prohibición del cuatrerismo local e interjurisdiccional, con la imposición, en cualquiera de los casos, de fuertísimas multas y castigos.(46)

\section{A modo de cierre.}

En el artículo planteamos la reunión de dos líneas disciplinares, la Historia Social y la Historia Política, a través de la historia de dos familias, que se relacionan vía matrimonio y cuyos hombres en el Cabildo asumen violentamente la cuestión reformista borbónico-carlista en el año 1772. Tal acción que involucra al gobernador y otras autoridades, clausuró el proceso del Estado Criollo en Santiago del Estero, en un momento que tanto la ciudad como la jurisdicción estaban atravesando momentos muy comprometidos por los alzamientos fronterizos contra la autoridad imperial y los criollos no estaban dispuestos a ceder su poderío capitular, que lo era también económico y de jerarquías sociales.

Podemos decir entonces, que con estas acciones el "estado criollo" que para América Latina en general se extiende entre 1650 y 1750, en Santiago del Estero se amplía hasta comienzos de 1770 según el ejemplo pre-citado, implosionando en 1772. La lentitud del ingreso de los agentes del orden borbónico, las disputas de poder hacia el interior del Cabildo entre los grupos criollos y borbónicos relacionados familiarmente, la orden de repoblamiento de la ciudad aunada al proceso de la expulsión de los jesuitas que retornó a las familias criollas a la ciudad y con ello las disputas por el poder en el Cabildo mientras la atención borbónica, por lo menos en un quinquenio, se concentraba en la expulsión de los jesuitas y las acciones de las Temporalidades subsiguientes, permitió un resquicio para el reposicionamiento de los criollos que supieron aprovecharlo muy bien. Será entonces, en función de esta última etapa de consolidación, que la acción de los agentes borbónicos, el 
chileno don Jospeh Miguel Zilvetti Pedraza Giraldez y el gipuzcoano don Francisco de Zuasnábar Ayarragaray, fue tan fuerte y decidida que torciendo el brazo al poderío criollo, volcó el poder hacia los borbónicos y la posibilidad de imponer una serie de reformas del rey Carlos III que venían muy rezagadas en su implementación local.

\section{Notas}

(1) Rossi, M. C. y Banzato, G. Tierra y Sociedad en Santiago del Estero. El antiguo Matará, siglos XVII a XX. Academia Nacional de la Historia de la República Argentina. Primer premio a Obras Inéditas, 2017b, en prensa; y Rossi, M.C. Las Reformas Borbónicas en Santiago del Estero, siglo XVIII. Algunas cuestiones para pensar los impactos en los contextos de una frontera imperial, Santiago del Estero, EDUNSE, 2017, en prensa.

(2) Andújar del Castillo, F. "Espacios de Poder en el seno del Ejército Borbónico: Coroneles, Inspectores y Guardias Reales”, en Álvarez Santaló, León Carlos (Coord). Estudios de Historia Moderna en Homenaje al Profesor Antonio García-Baquero, Sevilla, Universidad de Sevilla, Secretariado de Publicaciones Universidad de Sevilla, 2009.

(3) Rossi, Las Reformas borbónicas..., Op. Cit.

(4) Herzog, T. "La vecindad: entre condición formal y negociación continua. Reflexiones en torno a las categorías sociales y las redes personales", en Anuario del IEHS, 15, Tandil, Argentina, 2000.

(5) Hernández Franco, J. "El reencuentro entre historia social e historia política en torno a las familias de poder. Notas y seguimiento a través de la historiografía sobre la Castilla Moderna", en Studia historica. Historia moderna, 18, 1998, p. 14.

(6) Michels, R. Political Parties. A Sociological Study oí the Oligarchical Tendencies oí Modern Democracy, New Brunswick, Nueva Jersey, Transaction Publishers, 2009, pp. 342-356; Mosca, G. La clase política, México, FCE, 1984, pp. 91-112; Pareto, W. The Rise and Fall of the Elites. An Application of Theoretical Sociology, New Brunswick, Nueva Jersey, Transaction Publishers, 1991, pp. 73-90.

(7) Rossi, M.C. "Alfaro-Peñaloza-Urrejola Izarza. Las familias de la transición al temprano orden borbónico en Santiago del Estero - 1700-1750"; en Rey Castelao, Ofelia y Cowen, Pablo (Coords). Familias en el Viejo y Nuevo Mundo, Colección Editorial HisMundl, II, Historia del Mundo Ibérico, La Plata, Prosecretaria de Publicaciones de la FaHCE-UNLP, 2017. En línea recuperado de http://libros.fahce.unlp.edu.ar/index.php/libros/catalog/book/95

(8) Fue casado en primeras nupcias con María Jacinta Zilveti Paz y Figueroa (hija de Joseph Miguel y María Catalina) con quien tuvo cinco hijos formando la familia Alcorta Zilveti Paz. Cuando enviudó se casó con Gabriela de Zuasnábar Paz y Figueroa, sobrina de María Jacinta por parte de madre, con quien tuvo ocho hijos y formaron la familia Alcorta Zuasnábar. A su 
vez sus hijos volvieron a emparentar las familias cuando María Catalina de Alcorta Zilveti Paz se casó con José Ramón de Olaechea Zuasnábar, hijo de Margarita de Zuasnábar Paz y Figueroa. El hermano de José Ramón, Baltazar, se casó con Francisca Petrona de Alcorta Zuasnábar.

(9) Actas Capitulares de Santiago del Estero, en adelante ACSE-TII, 1748-1755, p. 226.

(10) ACSE-TII, 1748-1755, pp. 214-215.

(11) Ver: http://www.genealogiafamiliar.net/old/getperson.php?personID=185466\&tree=BVCZ

(12) Archivo General de la Nación, en adelante AGN-Sala XIII-Colonia-12-8-5. Libro Real Común General de Hacienda, Caja de Santiago del Estero, 1760.

(13) Bertrand, M. Grandeza y miseria del oficio. Los oficiall /les de la Real Hacienda de la Nueva España, siglos XVII y XVIII, México, Fondo de cultura Económica, 2011.

(14) ACSE-TII, 1748-1766, pp. 321-323.

(15) ACSE-TII, 1748-1766, pp. 340-341. En esa reunión participaron otros borbónicos en la misma calidad, don Agustín de Iramain, don Antonio García de Villegas, don Francisco Ximénez de Paz Parejas; y otros dos de los que no tenemos todavía mucha información, don Francisco de Orostegui y don Francisco de Inojosa (o: Hinojosa)

(16) ACSE-TII, 1748-1766, p. 364.

(17) ACSE-TII, 1748-1766, pp. 427-428.

(18) ACSE-TIII, 1767-1777, p. 112. O, por lo menos, no hay referencias en las Actas Capitulares de que esto haya ocurrido. El 5 de enero de 1767 se presentó ante el Cabildo de Santiago, don Gabriel Antonio de Salvatierra, vecino morador de la ciudad y en ese momento actuando como Comisionado de don Juan Manuel Campero, Coronel de Milicias del Perú, Teniente Coronel de los Reales Ejércitos, Superintendente de la Real Hacienda Ramos de Cruzada y Guerra y Gobernador y Capitán General de estas Provincia, trayendo una Real Provisión para confirmar las elecciones de Alcaldes Ordinarios, de la Hermandad y demás oficios, en el marco de unas elecciones discutidas por un conflicto con don Antonio Arias, que venía arrastrándose hacía varios años. En este marco fue electo don Joseph Miguel Zilveti, todavía con el grado de Sargento Mayor (recién para 1768 alcanzará el grado de Maestre de Campo), para el cargo de Alcalde de la Santa Hermandad (siendo su jefe don Roque López de Velasco que era Alcalde Mayor Provincial propietario). En el Acta se deja constancia de un dato que no figura en Actas anteriores, Zilveti se venía desempeñando como Protector General de Indios desde 1765 y que continuó desempeñándose en el mismo. Para ese entonces tenía unos 30 años. El Cabildo quedó conformado con el Maestre de Campo don Antonio Arias como Alcalde de 1er. Voto; Sargento Mayor don Francisco Avellaneda como Alcalde de 2o. Voto; Maestre de Campo don Diego Ignacio Martínez de Lezana como 
Procurador General y Mayordomo del Real Hospital; y don Juan Ignacio Cavallero como Defensor de Menores. Figura en la votación para el año de 1769.

(19) ACSE-Tomo II, 1748-1766, pp. 417-418. En el Acta Capitular figura simplemente con la calidad de vecino. Pero pensamos que posiblemente se trate de don José de Frías Suárez de Cantillana, bautizado en 1737 y casado con Casilda de Araujo Ibáñez en 1774.

(20) No tenemos muy en claro cuál fue el derrotero de esta situación, pero si sabemos que en la elección de 1769 en la que participó como "elegible" se dice que era Protector de Indios desde hacía años.

(21) ACSE-TIII, 1767-1777, p. 8. En tiempos posteriores al estudio que estamos realizando, lo veremos como Administrador de Correos en 1787 y Síndico del Convento de San Francisco. Fue uno de los borbónicos de mayor actividad en las Temporalidades y Administrador de la Reducción de Abipones luego de ser expulsados los Jesuitas. Otra de sus actividades fue la del comercio al que accedió bastante rápidamente desde su llegada.

(22) ACSE-TIII, 1767-1777, pp. 12-14 y 47.

(23) Linch, J. "El Reformismo borbónico en Hispanoamérica", en Guimerá, Agustín. El Reformismo borbónico, Madrid, Alianza Universidad, 1996, pp. 45-48.

(24) De padre guipuzcoano, don José de Iramain Arzamendi y padre potosina, doña Agustina Rodríguez Espinosa, llegaba desde Potosí donde nació en 1725. Una vez instalado en Santiago del Estero, contrajo matrimonio con doña Josefa de Santillán Luna y Cárdenas, en 1759 se desempeñará como Defensor de Menores. Para advertir la importancia que tenía el cargo, ver: Bertrand, Op. Cit.

(25) Llegó a Santiago del Estero en 1750 con el grado de Sargento Mayor y en 1761 obtuvo el grado de Maestre de Campo. En 1762 contrajo matrimonio con doña Lorenza de Luna y Cárdenas Vera y Aragón, hija del Maestre de campo don Francisco de Luna y Cárdenas.

(26) ACSE-TIII, 1767-1777, p. 218; Archivo Histórico de Santiago del Estero, en adelante AHSE-ST-L1-Exp.54-Letra R. El 26 de octubre de 1765 llegó a Santiago del Estero una Real Orden relativa a las condiciones que tendrían, en adelante, la venta de oficios renunciables y vendibles de los Reinos de Indias. El documento fue emitido por el Rey Carlos III, se prohibía que los hijos pudieran heredar o adquirir los cargos ejercidos por sus padres, y los beneficios obtenidos irían directamente a las Cajas Reales. Luego se estipulan una cantidad de condiciones que deberán seguir los aspirantes y el rol del Imperio.

(27) ACSE-TIII, 1767-1777, p. 219.

(28) Idem.

(29) ACSE-TIII, 1767-1777, pp. 28-219.

(30) ACSE-TIII, 1767-1777, pp. 221-222.

(31) ACSE-TIII, 1767-1777, p. 223.

Cuadernos de H Ideas, vol. 11, nº 11, diciembre 2017. ISSN 2313-9048 
(32) ACSE-TIII, 1767-1777, pp. 224-225.

(33) Idem.

(34) ACSE-TIII, 1767-1777, pp. 221-222.

(35) ACSE-TIII, 1767-1777, pp. 226-227.

(36) ACSE-TIII, 1767-1777, pp. 247-248.

(37) “...y, si así pudiera acontecer, también al Juez Privativo de todas las Juntas de la provincia de Tucumán y del Paraguay y del Río de la Plata, y gobernador y Capitán General de Buenos Aires, Señor Mariscal de Campo don Juan Joseph Ortiz de Ocampo". ACSE-TIII, 1767-1777, p. 249.

(38) ACSE-TIII, 1767-1777, pp. 245-246.

(39) Aramendi, B.M. "El Ramo de Bulas de la Santa Cruzada en el Tucumán Colonial", en Diálogo Andino, №33, Universidad de Tarapacá, Arica-Chile, 2009, pp. 59-74

(40) El año anterior se había desempeñado como Defensor de Menores.

(41) ACSE-TIII, 1767-1777, pp. 233-234.

(42) Aramendi, Op. Cit. ABHS, Fondos de Gobierno, Caja 1, 1606-1769; Caja 2 A, 17751776). También se contaba con notarios y contadores de Santa Cruzada, los cuales recibían un sueldo fijo (Los notarios no debían cobrar por los despachos tocantes a la Santa Cruzada contentándose con el sueldo que se les asignaba. ABHS, Fondos de Gobierno, Caja 9, 17861787. Madrid, 8 de enero de 1787. Los contadores cobraban 200 pesos por bienio)".

(43) Aramendi, Op. Cit.

(44) AHSE-AG-L4-Exp. 224-Año 1772.

(45) Rossi y Banzato, Op. Cit.

(46) ACSE-TIII, 1767-1777, pp. 252-253.

Recibido: agosto de 2017.

Aprobado: noviembre de 2017.

\section{Para citar este trabajo}

Rossi, M. C. "Las estrategias de las familias borbónicas para acceder al poder del Cabildo. Un estudio de caso en el Santiago del Estero durante la segunda mitad del siglo XVIII" en Cuadernos de H Ideas [En línea], $\quad$ vol. $\quad 11, \quad n^{\circ} \quad 11, \quad$ diciembre $2017, \quad$ consultado...; $\quad$ URL: http://perio.unlp.edu.ar/ojs/index.php/cps/article/view/4545 
Cuadernos de H Ideas, vol. 11, no 11, diciembre 2017. ISSN 2313-9048 